\title{
Risk Factors of Obesity among 15-64 Yrs Age Group: Picture in a Village of West Bengal
}

\author{
Gandhari Basu ${ }^{1}$, Baijayanti Baur ${ }^{2}$, Sutapa Mondal $^{3}$, Chitra Chatterjee ${ }^{4}$, Dipa \\ Saha ${ }^{5}$, Suman Kumar Roy ${ }^{6}$ \\ 1(Community Medicine, College of medicine \& JNM Hospital, Kalyani, India) \\ 2 (Community Medicine, Kolkata Medical College, India) \\ 3(Community Medicine, College of medicine \& JNM Hospital, Kalyani, India) \\ 4(Community Medicine, Kolkata Medical College, India) \\ 5(Physiology, College of Medicine \& JNM Hospital, Kalyani, India) \\ 6(Community Medicine, College of medicine \& JNM Hospital, Kalyani, India)
}

\begin{abstract}
Obesity, a result of unhealthy consumption, coupled lack of physical activity, is itself a serious health risk. The key to the control of epidemics of obesity is primary prevention. The basis of prevention is therefore identification of the major risk factors and their prevention and control. A Descriptive epidemiological study using cross sectional design was carried out among seven thirty subjects of 15-64 yr age group in a village with primary objective of finding out the prevalence of various risk factors and to see the association in between. Interview was taken using a schedule modified in line with IDSP questionnaire ${ }^{[11]}$ taking into account the local needs and resources. Data was collected on socio demographic variables, risk factors of obesity by house to house visit after obtaining informed verbal consent. Study population consisted of 57\% male, 70\% Hindu, 20\% illiterate and $35 \%$ unemployed respondents. 22.9\% gave smoked and smokeless tobacco use history, $75.2 \%$ current tobacco users, $21 \%$ current drinkers, $38.5 \%$ had sedentary lifestyle, nearly $50 \%$ added extra salt most of the times, $80 \%$ use unsaturated oil. Sixty subjects had BMI of more than 30.0. Significant association was found with age group, per capita income, tobacco use, alcohol consumption, physical activity, salt intake with food and intake of oils/fat. $(P<.01)$. Finally motivation for improvement in life style is the million dollar suggestion.
\end{abstract}

Key Words: Obesity, IDSP questionnaire, verbal consent, BMI.

\section{Introduction:}

Obesity is a condition in which excess body fat has accumulated to the extent that it may have an adverse effect on health, leading to reduced life expectancy and/or increased health problems. ${ }^{[1,2,3]}$ People are considered obese when their body mass index (BMI), exceeds $30 \mathrm{~kg} / \mathrm{m}^{2}{ }^{23]}$ Obesity increases the likelihood of various diseases, particularly heart disease, type 2 diabetes, obstructive sleep apnea, certain types of cancer, and osteoarthritis. ${ }^{[2]}$ Obesity is most commonly caused by a combination of excessive food energy intake, lack of physical activity, and genetic susceptibility, although a few cases are caused primarily by genes, endocrine disorders, medications or psychiatric illness. Behavioral risk factors such as tobacco use, alcohol consumption, low consumption of fruit and vegetables and a lack of physical activity lead to the intermediate risk factors. Obesity, a result of unhealthy consumption, coupled lack of physical activity, is itself a serious health risk, although Indians have less conventional risk factors still they succumb to the claws of this disease. The key to the control of epidemics of obesity is primary prevention. The basis of prevention is therefore identification of the major risk factors and their prevention and control. Dieting and physical exercise are the mainstays of treatment for obesity. Diet quality can be improved by reducing the consumption of energy-dense foods such as those high in fat and sugars, and by increasing the intake of dietary fiber. Anti-obesity drugs may be taken to reduce appetite or inhibit fat absorption together with a suitable diet. If diet, exercise and medication are not effective, a gastric balloon may assist with weight loss, or surgery may be performed to reduce stomach volume and/or bowel length, leading to earlier satiation and reduced ability to absorb nutrients from food. ${ }^{[4][5]}$ Obesity is a leading preventable cause of death worldwide, with increasing prevalence in adults and children, and authorities view it as one of the most serious public health problems of the 21 st century ${ }^{[6]}$ Obesity is stigmatized in much of the modern world (particularly in the Western world), though it was widely perceived as a symbol of wealth and fertility at other times in history, and still is in some parts of the world. ${ }^{[7]}$

In 1997 the WHO formally recognized obesity as a global epidemic. ${ }^{[8]}$ As of 2008 the WHO estimates that at least 500 million adults (greater than 10\%) are obese, with higher rates among women than men. ${ }^{[9]}$ The rate of obesity also increases with age at least up to 50 or 60 years old. ${ }^{[10]}$ Once considered a problem only of high-income countries, obesity rates are rising worldwide and affecting both the developed and developing 
world. ${ }^{[11]}$ There are limited data on prevalence of risk factors in rural population. Therefore present study was carried out to estimate the prevalence of various risk factors for obesity and to identify their biosocial association in a village of West Bengal. The study was carried out keeping the following objectives in mind. Firstly, to find out the prevalence of behavioral risk factors and to determine presence of association, if any, between the socio demographic variables, risk factors with obesity.

\section{Methods:}

A Descriptive epidemiological study using cross sectional design was carried out among 15-64 yr age group population residing in a village of Singur block of Hoogly district, West Bengal. The duration was 6 months (May'08 - October'08). The village under study was selected by simple random sampling from a list of total 63 villages obtained from the register of rural health unit and training centre, Singur Block of Hoogly district, West Bengal. The village had a registered population of 1265.This training centre was under AIIH \& PH, Kolkata. The community was very cooperative. All males and females between 15-64 year age group were considered as the eligible population to be included under study. The eligible population of that village was 789 during the study period. There were some exclusion criteria like acute illness, deaf \& mute person, communication barrier, pregnant woman. Pregnant women were excluded as there were differences in practicing of risk factors due to their present physiological condition, which was not so before pregnancy. This was likely to create biases in the outcome of the present study. Out of the eligible population, 11 people did not agree to take part due to various reasons, 15 people were not in position to take part due to either illness or communication barrier and 33 were pregnant female. Therefore the final study population came to 730. Permission was obtained from the ethical committee. Interview was taken using pre designed, pre tested and semi structured schedule, modified in line with IDSP questionnaire ${ }^{[11]}$ taking into account the local needs and resources after pre testing in local language. This questionnaire focused on self-reported information on behavioral risk factors, like tobacco usage, alcohol consumption and many others. Data was collected on socio demographic variables, behavioral risk factors of obesity by house to house visit. Informed verbal consent was obtained from each subject. The risk factors for obesity considered under the study were tobacco use, alcohol consumption, physical inactivity, vegetable intake, fruit intake, extra salt intake with food, intake of oils. For tobacco use' 5 subgroups were taken namely, current user (someone who at the time of survey, smokes/uses tobacco in any form either daily or occasionally), daily user (someone who smokes/uses tobacco at least once a day and people who smoke/use tobacco every day with rare exceptions such as not on days of religious fasting or during acute illness are still classified as daily smokers), occasional user (someone who smokes/ uses tobacco, but not on every day), never user ( those who have never smoked at all), ex- user (people who were former daily smokers but currently do not smoke at all or those who were former occasional smokers). For alcohol consumption, 4 subgroups were selected. Firstly current drinker ( those who consumed 1or more drinks of any type of alcohol in the year preceding the survey), secondly former drinker(those who have ever drunk alcohol but those who did not consume 1 or more drinks during the year preceding survey), thirdly lifetime abstainer (those who never consumed 1 or more drinks of any type of alcohol) and finally high-risk drinker (those who drink more than 5 (for women 4) standard drinks on any single day). For physical activity categorization, it was assessed by a scoring method that was developed by the researcher after giving scores to individual question in the physical activity category. This scoring range was different in case of people working outdoors and people working indoors. Based on the scoring, the amount of activities undertaken as part of work was measured and classified as being of sedentary or inactive, moderate, heavy physical activity. For those people who work outdoors having sedentary or inactive life scored between $0-4$, while subjects having moderate activity had score between 5- 8 and subjects having heavy activity scored between 9-12. For those people who stay or work indoors, having sedentary or inactive life scored between $0-2$, while subjects having moderate activity had score between 3-4 and subjects having heavy activity scored between 5-6.The amount of salt intake with food was quantified and the participants were stratified into 3 categories like low intake group/Never or rarely: Those who do not add salt to their food while cooking and while eating food. Moderate intake group/sometimes: those who add salt to food only while cooking and high intake group /most of the times: those who add salt to food while cooking and while eating. For overweight and obesity, subjects were classified using WHO classification. ${ }^{[12]}$ In the present study, people having BMI between25.00 - 29.99 were considered as overweight and BMI of $>30.00$ regarded as obese. Obesity also considered ${ }^{[13]}$ in men with waist circumference $>=102 \mathrm{~cm}$ and women with a waist circumference $>=88 \mathrm{~cm}$. After collection of data, all of them were coded, entered into MS Excel, double checked, and analyzed with EPI- INFO (version-3.4.3). For categorical risk factors, contingency tables were used and the strength of association was measured using the Chi-squared test $\left(\chi^{2}\right)$. If there were less than 5 cases in any cell of the contingency table, they were pooled with the other relevant group. P value was considered significant if $\mathrm{P}<0.01$. 


\section{Results:}

The present study population had $56.7 \%$ males and $43.3 \%$ females. Two eighty five $(45.9 \%)$ were $<35$ yrs whereas around $15 \%$ were $>55 \mathrm{yrs}$ of age. Mean age of male is less (36.49yrs) than female (38.13yrs). Out of population under study, majority were Hindus (69.9\%).145 out of 730 were illiterate or just literate. Only $23.3 \%$ of study populations had more than secondary level education. Illiteracy were more prevalent among females than males $(29.7 \%$ vs. $12.3 \%)$, whereas higher education were more or less similar among both sexes $(5.8 \%$ vs. $7.3 \%)$. Males acquired more middle $(37.7 \%)$ and secondary $(22.2 \%)$ education in comparison to females $(23.4 \%$ and $11.1 \%$ respectively).It was seen that, $34.8 \%$ of study population were unemployed.33.8\% were unskilled labor, $8.2 \%$ were skilled labor, $2.7 \%$ engaged in service, $12.1 \%$ had business and $8.4 \%$ were student. Prevalence of unskilled labors was more in males $(37.4 \%)$ than females $(29.1 \%)$. $55.4 \%$ of females were found to be homemaker. 419 subjects fall between $1^{\text {st }}$ quartile and $2^{\text {nd }}$ quartile (rs. $750 /-$ to rs. $\left.1100 /-\right) .43 \%$ belong to $3^{\text {rd }}$ and $4^{\text {th }}$ quartile. (rs.1650/- to rs.2500/-). The median PCI was Rs.1100/-per month.(Table I)

Table II depicted the prevalence of various risk factors among the respondents. $12.3 \%$ of study population used smoked tobacco products whereas $40 \%$ used smokeless tobacco products. $22.9 \%$ of study population used both.(table II) Only $24.8 \%$ were not using tobacco products in any form. $11.6 \%$ were using cigarette, $29.0 \%$ using bidi,4.5\% took snuffs and $18.8 \%$ took chewed tobacco, while $51 \%$ were users of gutkha. $75.2 \%$ of study population was current tobacco users whereas $13.9 \%$ were past or ex users and $10.8 \%$ did not use tobacco products at all. Current tobacco usage was seen more among females (76.6\%) than males $(74.1 \%)$. Median age of starting of tobacco products was 16 years in male, 18 years in females. It was seen in the present study that among current tobacco users, the mean number of years of current tobacco use was marginally higher among males (19.62) than females (18.0). The average years of tobacco use had been increased as age advanced in both sexes. It was seen that $7.5 \%$ of study population was high risk drinkers whereas $21 \%$ were current drinkers and $9.9 \%$ were former drinkers.61.6\% of study population were life time abstainers. No females under study reported alcohol consumption. Among current drinkers, the mean age of commencing drinking was 18yrs. Physical inactivity was present in $38.5 \%$ of study population. Heavy physical activity was carried out by 198 subjects. Only $0.9 \%$ of population practiced yoga.6.2\% considered their physical activity to be light, whereas $33.8 \%$ thought their physical activity to be moderate and $30.5 \%$ considered themselves to be heavily active physically. $38.7 \%$ of population (who work outdoors) spent 7-8 hours at work whereas $49.5 \%$ ) spent more than 8 hrs at work. Only $2.9 \%$ of study population spent $<=4 \mathrm{hrs}$ at work. It had been observed that only $1.5 \%$ did slow walking, $0.9 \%$ did brisk walking, $0.4 \%$ did jogging, $1.9 \%$ did cycling at times, $4.8 \%$ involved in physically active games. Regarding the dietary habit, it was seen that $46.2 \%$ of study population took vegetables $3-4$ times a week and $40.8 \%$ of study population took fruits regularly / 3-4 times a week. Majority (49.5\%) of study population added extra salt most of the times after food was served. Only $19.7 \%$ did not take extra salt with food. Unsaturated oil was used by majority $(79.6 \%$ ) of study population whereas $20.4 \%$ study population consumed saturated oils/fat (table II).Mustard oil was most commonly (64.4\%) used followed by sunflower oil (8.5\%) and white oil $(6.7 \%)$ among unsaturated oils. Ghee was most commonly used (14\%), followed by coconut oil (6.4\%).

$15.9 \%$ were underweight whereas overweight was noticed among 149 subjects. Sixty subjects had BMI of more than 30.0.Mean weight, height, waist circumference and BMI of the study population was $56.82 \mathrm{~kg}, 155.43 \mathrm{~cm}$, $77.69 \mathrm{~cm}$ and 23.53 respectively. It was seen that mean BMI had been increased up to 44 yrs and then a plateau phase reached. Mean weight and BMI was more in females. Central obesity was present in $19.04 \%$ of study population, out of which more prevalence was recorded in females $(54.7 \%)$.

Table III and IV showed the association of overweight or obesity with socio demographic variables and different behavioral risk factors. Significant association was found with age group, per capita income, tobacco use, alcohol consumption, physical activity, salt intake with food and intake of oils/fat. $(\mathrm{P}<.01)$

\section{Discussion:}

In the present study, there were 730 subjects between $15-64$ yrs age comprising of $56.7 \%$ males and $43.3 \%$ females. A study ${ }^{[14]}$ included 121 subjects of $15-64$ yrs and among them $46.3 \%$ was males and $53.7 \%$ were females. So it was seen that in present study the percentage of females were less than reference studies and this is in true sense a matter of concern. In the present study, 84.9\% of population were in 15-54 yrs which was quite similar (88\%) to the study done by Mehan M B et al. ${ }^{15}$ In present study, $69.9 \%$ were Hindus, $30.1 \%$ Muslims.42.6\% lived in nuclear family. $10.8 \%$ were unemployed. $33.8 \%$ unskilled labor, $8.2 \%$ skilled labor, $2.7 \%$ engaged in service, $12.1 \%$ had business and $8.3 \%$ were students. $55.4 \%$ of females were homemaker. The study done by Mehan M B et al ${ }^{[15]}$ revealed that, $84.3 \%$ lived in nuclear family. $94.2 \%$ were Hindus, $2.5 \%$ were Muslims.62.8\% had graduate level education, $14.9 \%$ had high school education. $33.1 \%$ were homemakers, $28.1 \%$ non government employees, $13.2 \%$ self-employed, $10.7 \%$ government employees, $9.9 \%$ retired persons,5\% students. Regarding level of education, $19.9 \%$ of study population were illiterate, $24.8 \%$ had primary, $17.4 \%$ had secondary, $6.4 \%$ had higher level of education. Illiteracy were more prevalent among females than males $(29.7 \%$ vs. $12.3 \%)$, whereas higher education were more or less similar among both sexes (5.8\% vs. $7.3 \%)$. Prevalence 
of tobacco use was less in some studies ${ }^{[15,16]}$ that might be due to different locations, huge variation in age range and socio cultural differences. $12.3 \%$ of study subjects used smoked tobacco products whereas $40 \%$ used smokeless tobacco products and $22.9 \%$ of study populations used both and this was less than what found in another study carried out by Sinha D N et al. ${ }^{[17]}$ In the present study, the findings of physical activity were quite similar to a study carried out by Sugathan T N et al. ${ }^{[18]} 20.4 \%$ of present study population consumed saturated oils/fat which was far less than the percentage (47\%) found in a study done in rural area by Agarwal V K et al. [19]

In the present study, the prevalence of overweight and obesity was $28.6 \%$ where $20.4 \%$ were were overweight and $8.2 \%$ were obese. The findings were similar with some studies. ${ }^{[15,20]}$ Present study elicited higher prevalence among females $(31.2 \%$ vs $26.6 \%)$. This result was found to be similar with some other studies. ${ }^{[20,21,22,}$ ${ }^{23]}$ Central obesity using waist circumference cut offs was present for $15.2 \%$ males and $24.1 \%$ females in present study. In a study by Anand $\mathrm{K}$ et al ${ }^{[23]}$ the percentage was $3.5 \%$ and $20.6 \%$ respectively. Mean BMI of females was more than males in this study and similar findings were found in same one. ${ }^{[23]}$ An association with age group and per capita income was there in this study similar with some study. ${ }^{[20,21]}$ The present study showed significant association of overweight / obesity with behavioral risk factors and similar results were there in some other studies. ${ }^{[24,25]}$

\section{Conclusion:}

The final conclusion had come from the study was that the study population lacked healthy lifestyle in terms of behavioral risk factors. It was seen that one fifth of the respondents were either illiterate or just literate which was really a matter of concern. Therefore the local administrative authority to take an active step in arranging some health awareness campaign in grassroots level at regular interval to improve the lifestyle of the respondents. Active participation of the people could be elicited by proper motivation.

\section{Acknowledgement:}

We sincerely thank all the respondents of the village besides whose active co-operation and sincere support this study can never see daylight. Personal thanks to Prof. Madhumita Dobe, late Prof. Ranadeb Biswas of All India Institute of Hygiene \& Public Health for their continuous support and motivation throughout the study period.

\section{TABLES:}

TABLE [I]: Socio demographic profile of study population $(\mathrm{N}=730)$

\begin{tabular}{|ll|}
\hline Variables & Number $(\%)$ \\
Age group & \\
<35 yrs & $335(45.9)$ \\
$35-54$ yrs & $285(39.0)$ \\
55-64yrs & $110(15.1)$ \\
Sex & \\
Male & $414(56.7)$ \\
Female & $316(43.3)$ \\
Religion & \\
Hindu & $510(69.9)$ \\
Muslim & $220(30.1)$ \\
Family type & \\
Nuclear & $311(42.6)$ \\
Joint & $419(57.4)$ \\
Level of education & \\
Illiterate/Just literate & $145(19.9)$ \\
Primary/middle & $411(56.3)$ \\
Secondary/ Higher & $174(23.8)$ \\
Employment status & \\
Unemployed & $254(34.8)$ \\
Employed & $415(56.8)$ \\
Student & $61(8.4)$ \\
Per capita income per month & \\
$1^{\text {st }}$ 2 $^{\text {nd }}$ quartile & $419(57.4)$ \\
$3^{\text {rd }-4^{\text {th }} \text { quartile }}$ & $311(42.6)$ \\
\hline
\end{tabular}


TABLE [II]: Prevalence of risk factors $(\mathrm{N}=730)$

\begin{tabular}{|c|c|}
\hline Risk factors & Number (\%) \\
\hline \multicolumn{2}{|l|}{ Type of tobacco use } \\
\hline Only Smoked tobacco products & $90(12.3)$ \\
\hline Only Smokeless tobacco products & $292(40.0)$ \\
\hline Smoked and smokeless tobacco products(both) & 167 (22.9) \\
\hline \multicolumn{2}{|l|}{ Type of drinkers (Frequency of drinking) } \\
\hline High risk drinker (Equal / > 5 days a wk) & $55(7.5)$ \\
\hline $\begin{array}{l}\text { Current drinker (1-4 days a week/ } 1-3 \text { days a month/less } \\
\text { than once a month) }\end{array}$ & $59(8.1), 94(12.9)$ \\
\hline Former drinker & $72(9.9)$ \\
\hline Life time abstainer & $450(61.6)$ \\
\hline \multicolumn{2}{|l|}{ Physical activity } \\
\hline Sedentary/Inactive & $281(38.5)$ \\
\hline Medium & $251(34.4)$ \\
\hline Heavy & $198(27.1)$ \\
\hline \multicolumn{2}{|l|}{ Vegetable intake } \\
\hline Regularly/3-4times a week & 337 (46.2) \\
\hline Sometimes/never & $393(53.8)$ \\
\hline \multicolumn{2}{|l|}{ Fruit intake } \\
\hline Regularly/3-4times a week & $298(40.8)$ \\
\hline Sometimes/never & $432(59.2)$ \\
\hline \multicolumn{2}{|l|}{ Extra salt intake with food } \\
\hline Most of the times & $361(49.5)$ \\
\hline Sometimes & $225(30.8)$ \\
\hline Rarely/Never & 144 (19.7) \\
\hline \multicolumn{2}{|l|}{ Intake of oils/fat } \\
\hline Unsaturated oils & $581(79.6)$ \\
\hline Saturated oils/fat & $149(20.4)$ \\
\hline
\end{tabular}

TABLE [III]: Obesity and socio demographic variables (N=730)

\begin{tabular}{|c|c|c|c|c|}
\hline \multirow{2}{*}{\multicolumn{2}{|c|}{ Socio demographic variables }} & \multicolumn{3}{|c|}{ Overweight / Obesity } \\
\hline & & Present & Statistics & OR ( $95 \%$ CI ) \\
\hline \multirow{5}{*}{$\begin{array}{ll}\begin{array}{l}\text { Age } \\
(\text { yrs })\end{array} & \text { group }\end{array}$} & 15-24yrs $(n=190)$ & 37 (19.5) & $x^{2}=22.01$ & $0.40(0.24-0.67)$ \\
\hline & $25-34 y r s(n=145)$ & $39(26.9)$ & $P=.000$ & $1.64(0.97-2.77)$ \\
\hline & $35-44 y r s(n=149)$ & $56(37.6)$ & & 1 \\
\hline & 45-54yrs $(n=136)$ & $33(24.3)$ & & $0.53(0.31-0.92)$ \\
\hline & $55-64 y r s(n=110)$ & 44(40) & & $0.90(0.53-1.55)$ \\
\hline \multirow{2}{*}{ Sex } & Male $(n=414)$ & $209(28.6)$ & $x^{2}=1.76$ & \\
\hline & Female $(n=316)$ & $110(26.6)$ & $P=.18$ & $1.26(0.90-1.76)$ \\
\hline \multirow[t]{5}{*}{$\begin{array}{l}\text { Level of } \\
\text { education }\end{array}$} & $\begin{array}{l}\text { Illiterate/Just literate } \\
(n=145)\end{array}$ & & $x^{2}=9.88$ & \\
\hline & Primary $(n=181)$ & 209(28.6) & $P=.04$ & $0.49(0.29-0.81)$ \\
\hline & Middle (n=230) & $56(38.6)$ & & $0.56(0.35-0.90)$ \\
\hline & Secondary (n=127) & $44(24.3)$ & & $1.10(0.66-1.77)$ \\
\hline & Higher $(n=47)$ & $\begin{array}{l}\text { 60(26.5) } \\
38(29.9)\end{array}$ & & 1 \\
\hline \multirow{5}{*}{$\begin{array}{l}\text { Per capita } \\
\text { income } \\
\text { (quartile) }\end{array}$} & 1st $(n=212)$ & & & $0.83(0.50-1.38)$ \\
\hline & $2 n d(n=207)$ & $11(23.4)$ & $x^{2}=21.80$ & $0.87(0.39-1.90)$ \\
\hline & 3rd $(n=202)$ & $209(28.6)$ & $P=.000$ & \\
\hline & 4th $(n=109)$ & $52(24.5)$ & & 1 \\
\hline & & $45(21.7)$ & & 1.17(0.72-1.89) \\
\hline \multirow{8}{*}{$\begin{array}{l}\text { Employment } \\
\text { status }\end{array}$} & Unemployed $(n=79)$ & & & \\
\hline & Unskilled labor $(n=247)$ & $62(30.7)$ & $\begin{array}{l}x^{2}=5.34 \\
P=34\end{array}$ & $1.36(0.86-2.15)$ \\
\hline & Skilled labor $(n=60)$ & $50(45.9)$ & & 2.61(1.55-4.39) \\
\hline & Service $(\mathbf{n}=\mathbf{2 0})$ & $209(28.6)$ & & \\
\hline & Business $(\mathbf{n}=\mathbf{8 8})$ & $20(25.3)$ & & $1.17(0.63-2.17)$ \\
\hline & Student $(n=61)$ & $70(28.3)$ & & 1 \\
\hline & Homemaker $(n=175)$ & $20(33.3)$ & & $0.59(0.30-1.17)$ \\
\hline & & $2(10)$ & & $3.56(0.77-22.82)$ \\
\hline
\end{tabular}


TABLE [IV]: Obesity and risk factors ( $N=730)$

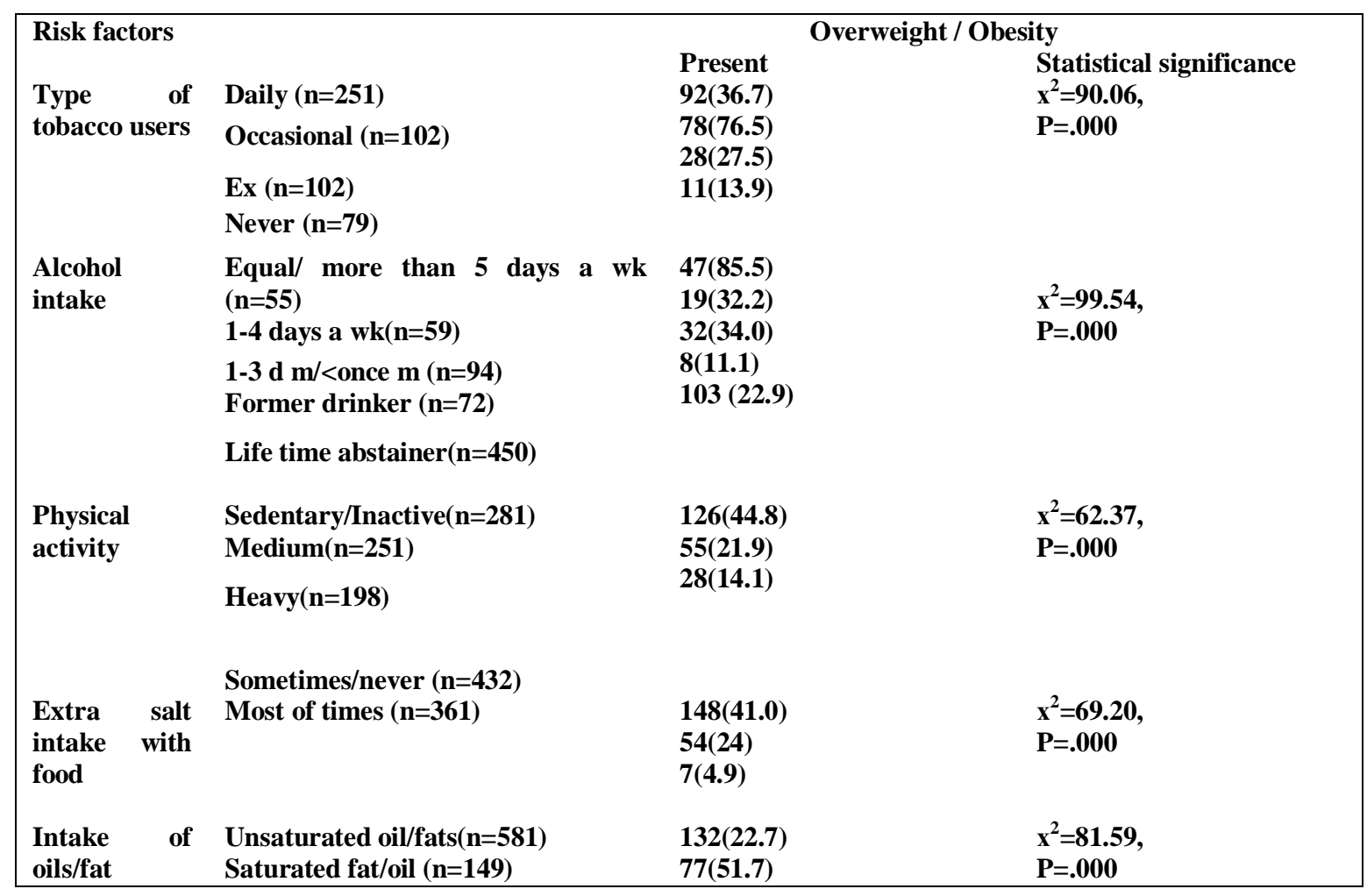

\section{References :}

[1] World health organization report 2000. p.6

[2] Haslam DW, James WP (2005). Obesity . Lancet 366 (9492): 1197-209.

[3] World health organization report 2000. p.9

[4] NICE 2006. p.10-11

[5] Imaz I, Martínez-Cervell C, García-Alvarez EE, Sendra-Gutiérrez JM, González-Enríquez J. Safety and effectiveness of the intragastric balloon for obesity. A meta-analysis. Obes Surg 2008; 18 (7): 841-6.

[6] Barness LA, Opitz JM, Gilbert-Barness E (December 2007). Obesity: genetic, molecular, and environmental aspects. Am. J. Med. Genet. A 2007; 143A (24): 3016-34.

[7] Woodhouse R. Obesity in art: A brief overview. Front Horm Res. Frontiers of Hormone Research 2000; 36: 271-86.

[8] Caballero B. The global epidemic of obesity: An overview. Epidemiol Rev2007; 29: 1-5.

[9] Obesity and overweight: World Health Organization. Retrieved April 8, 2009.

[10] Seidell 2005 p.5

[11] Tsigosa C, Hainer V, Basdevant A, Finer N, Fried M, Mathus V et al. Management of Obesity in Adults: European Clinical Practice Guidelines. The European Journal of Obesity 2008; 1 (2): 106-16.

[12] World Health Organization. Obesity- Preventing and managing the global epidemic. WHO technical report series 894.Geneva: WHO; 1999.

[13] 15. Park K. In: Park's Text book of preventive and social medicine; 15th ed. Jabalpur: M/S Banaroidas Bhanot Publishers; 1997.p. 268-301.

[14] Microsoft Word - annual report - 2008.

[15] Mehan M B, Surabhi S, Solanki G T. Risk factor profile of non-communicable diseases among middle-income (18-65 years)freeliving urban population of India.Int J Diab Dev Ctries2006; 26:169 (76).

[16] Chow C, Cardona M, Raju P, Iyengar S, Sukumar A, Raju R et al. Cardiovascular disease and risk factors among 345 adults in rural India - the Andhra Pradesh Rural Health Initiative. Int J of Cardiology; 116 (2);180-185.

[17] Sinha D N, Gupta P C, Pednekar M S. Tobacco use in a rural area of Bihar,India.Indian Journal of Community Medicine 2003 ; 28 (4).

[18] Sugathan T N, Soman C.R, Sankaranarayanan K. Behavioral risk factors for non communicable diseases among adults in Kerala, India. Indian J Med Res 2008 ;(127) pp 555-563.

[19] Agrawal VK, Bhalwar R, Basannar D R. Prevalence and Determinants of Hypertension in a Rural Community. MJAFI 2008 ; 64 : 21-25.

[20] Gupta R, Misra A, Vikram NK, Kondal D, Gupta SS, Agrawal A, Pandey RM. Younger age of escalation of cardiovascular risk factors in Asian Indian subjects. BMC Cardiovasc Disord. 2009; 9:28.

[21] Sugathan T N, Soman C.R , Sankaranarayanan K. Behavioral risk factors for non communicable diseases among adults in Kerala, India. Indian J Med Res $2008 ;(127)$ pp 555-563.

[22] Krishnan A, Shah B, Lal V, Shukla DK, Paul E, Kapoor SK. Prevalence of risk factors for non communicable diseases in a rural area of Faridabad district of Haryana. Indian J Public Health. 2008; 52(3):117-24. 
[23] Ananda K, Shah B, Yadav K, Singh R, Mathur P, Paul E, Kapoor S K. Are the urban poor vulnerable to non-communicable diseases? A survey of risk factors for non-communicable diseases in urban slums of Faridabad. National Med J India 2007;20:11520.

[24] Raina D J, Jamwal D S. Prevalence Study of Overweight/Obesity and Hypertension among Rural Adults. JK SCIENCE 2009;11 (1):1-4.

[25] 76. Xu F, Yin X M, Wang Y. The association between amount of cigarettes smoked and overweight, central obesity among Chinese adults in Nanjing, China. Asia Pac J Clin Nutr 2007;16(2):240-247. 